\title{
Artigos
}

\section{ARQUITETURAS DE UM CORPO \\ UTÓPICO NO COLETIVO AS TRAVESTIDAS}

\section{ARCHITECTURES OF A UTOPIAN BODY IN THE COLLECTIVE AS TRAVESTIDAS}

\section{ARQUITECTURAS DE UN CUERPO UTÓPICO EN EL COLETIVO AS TRAVESTIDAS}

Manoel Moacir Farias Júnior

Manoel Moacir Farias Júnior Doutorando em artes cênicas pela ECA-USP, por onde é mestre. Especialização pela Universidade Dom Bosco em docência no ensino superior e licenciatura em letras pela Universidade Federal do Ceará. Tem interesse em estudos e ações interdisciplinares, como artista-pesquisador, sobre literatura e cena contemporânea, cartografias ou histórias das artes e educação 


\section{Resumo}

Este artigo expõe uma visão cartográfica sobre três peças do coletivo As Travestidas, de Fortaleza. Busca um diálogo com ideias de Foucault e Preciado sobre corpo e política como questões importantes para esses artistas e que estão presentes em seus processos de criação.

Palavras-chave: Teatro brasileiro, Transexualidade, Performance.

\section{Abstract}

This article shows a cartographic point of view on three plays by the collective As Travestidas, from Fortaleza. It seeks a dialogue with ideas of Foucault and Preciado about body and politics as important issues for these artists, and that are present in their creative processes. Keywords: Brazilian theater, Transsexuality, Performance.

\section{Resumen}

Este artículo presenta una visión cartográfica de tres piezas del coletivo As Travestidas, de Fortaleza. Busca un diálogo con ideas de Foucault y Preciado sobre cuerpo y política como cuestiones importantes para eses artistas y que están presentes en sus procesos creativos.

Palabras clave: Teatro brasileño, Transexualidad, Performance.

\section{De onde partimos}

Com o intuito de cartografar a cena contemporânea de Fortaleza, selecionamos casos a partir da década de 1990 e apresentamos as poéticas dos artistas Ricardo Guilherme, Sílvia Moura e seus respectivos grupos como exemplos e objetos de estudos que cultivam novos modos de percepção e criação nas artes cênicas dessa cidade. Em seguida, passamos a grupos e coletivos atuais, como Curto-circuito, Soul e EmFoco, que engendram uma relação de pesquisa na fronteira com a performance e a prática site specific. Ao falar de cada caso, procuramos expor nossas próprias construções (perspectivas críticas e afetivas) sobre seus procedimentos de linguagem. 
Com um olhar cartográfico ${ }^{1}$ para essa produção recente, buscamos resgatar também os processos de criação e recepção. O que se esboça aqui é ainda uma forma de escrever sobre processos vistos há poucos anos, meses ou semanas. É também uma aposta em apreender movimentos da história do teatro brasileiro fora do eixo Rio de Janeiro-São Paulo, contribuindo para sua discussão como campo de estudos.

Em nossa rota, temos ainda artistas como David da Paz, Ítalo Adler, Naiana Magalhães e os grupos Teatro Mimo, Inquieta Cia., Balbucio, Projeto CadaFalso, Cia. Andanças, Grupo Bagaceira, Teatro Máquina, Cia. Dita, No Barraco da Constância Tem, Teatro Esgotado e Teatro em Película. Essa nova cena também tem encontrado espaço em vídeos-performances de Alexandre Veras, Leonardo Mouramateus, Yuri Firmeza, Marina de Botas e Milena Travassos etc.

O formato de ensaio que escolhemos sem dúvida traz algumas lacunas ao recusar ser uma história de cenas performativas, mas pretende ir além do registro crítico do produto de cada performance ou peça para tocar em questões que atravessam processos de criação diversos, diferenciando ou conectando-os. Esse foi um dos nossos objetivos ao analisar três diferentes trabalhos cênicos do coletivo As Travestidas.

\section{Cenas travestidas}

Espetáculos com casa lotada... Eventos de moda, shows de boate, calendários (translendários) ${ }^{2}$, festivais de orgulho gay e de teatro, dentro e fora do Brasil. Uma mulher barbada, números musicais e de dublagem. São essas as primeiras imagens que nos ocorrem ao pensar nesse grupo de artistas vindos do teatro, da música e da dança do atual cenário artístico fortalezense.

1. Como nos dizem Amador e Fonseca: "Assim, como um coletivo de forças, forja-se o material de pesquisa enquanto mapa, convocando o cartógrafo a acompanhar seu traçado em uma tarefa possível apenas pela criação de um território para habitar enquanto pesquisador: é de dentro enquanto fora que se pode operar uma cartografia. É incursionando pelo campo, em uma postura sensível ao seu fora, que o pensamento daquele que pesquisa pode fecundar um material empírico e vice-versa". (2009, p. 34)

2. O translendário, como exemplo dessas ações, foi um projeto do coletivo em 2012 e 2013 que trouxe fotos das artistas imitando imagens famosas da história da arte. Pode ser visto em reportagens como a do link: <http://g1.globo.com/ceara/fotos/2012/05/veja-imagens-das-paginas-do-translendario.html\#F441917>. 
Em 2009 começaram a circular esses trabalhos, que envolviam dublagem de musicais e um solo do ator Silvero Pereira ${ }^{3}$, o Cabaré da dama. Já nessas apresentações chamou atenção a exuberância de formas, cores e diferentes tons de vozes. As vozes das travestidas são coloridas, altas e desafinam. Em geral trazem em si a marca do desafio a uma ordem heterossexual de comportamento e sobre aquilo que está por demais seco e petrificado: o preconceito. Invertem, assim, o sentido de masculino e feminino ao dublar canções pop, do jazz, do axé ou da lambada, em tons agudos ou graves. Há sempre o desejo de aparecer como uma exclamação diante da vida: Eu sou assim!

Mas não se trata apenas de mais uma bandeira levantada ou da imposição de um sentido de cunho social para o espectador, mas de uma forma de dizer, com o discurso da cena, as potencialidades desse corpo transformista e transformado. Existe uma vinculação do grupo inicialmente ao teatro, uma vez que muitos estudaram ou se conheceram em cursos e grupos de Fortaleza. Há também ecos de uma produção musical e marginal que nos remetem ao já clássico Dzi Croquettes, se quisermos pensar em filiações estéticas para validar como arte o trabalho das Travestidas.

A questão "Isso é arte ou show de boate?" surgiu cedo na vida desse coletivo. Na abertura de uma exposição no Centro Cultural Dragão do Mar, no final de 2014, seus integrantes expuseram em uma conversa com o público a necessidade de se afirmarem como artistas que transitavam por um teatro que não se ligava mais a um texto e a personagens dramáticas e que deu voz aos seus anseios de criação de novos corpos que expressassem sua autoria. Esse processo não se limita à dublagem ou à imitação de coreografias da música pop, mas também se liga a um treinamento específico e uma visão de mundo que ri, com graça e deboche, das máscaras sociais.

O corpo do bufão é base comum em seu ritual de preparação, disseram, mas cada um parece muito à vontade para dar seu tom pessoal na criação de uma figura travestida. Vemos, por exemplo, que a dança contemporânea, a clássica e o butô aparecem como matrizes de movimento na atuação de Yasmin Sheerah. O humor escrachado é mais fortemente explorado pela veia

3. Uma flor de dama, inspirado em texto de Caio Fernando Abreu. Foi criado por Silvero, apresentado em diversos espaços alternativos desde 2005 e incorporado ao espetáculo Cabaré da dama. 
cômica de Deydiane Piaf. E assim, nomes são montados com a mesma lógica de remixagem que organiza corpos e cenas, como é o caso de Gisele Almodovar ou Alicia Pietá.

\section{BR Trans}

A ligação de Silvero Pereira com o universo transexual começou quando ele passou a morar, por volta dos anos 2000, em uma comunidade na qual tinha contato com travestis que se prostituíam e que durante o dia eram humilhadas pelos mesmos homens que as procuravam à noite. Algumas chegaram, inclusive, a ser mortas. Gisele Almodovar é uma das figuras às quais Silvero recorre para mostrar a dor de existir nesses limites de sobrevivência.

Sua performance é feita em um palco com poucos elementos de camarim, acompanhada por teclados, microfones, vídeos e músicas. Sua voz muda ao incorporá-la e seu corpo toma uma atitude mais feminina, elegante, combativa, explicando em espanhol como foram e quanto custaram suas operações para remodelar o corpo, em uma clara anexação da fala de Agrado no filme Tudo sobre minha mãe, de Pedro Almodóvar.

A citação à Almodóvar não é em vão. O diretor, seu filme e a personagem em questão são alguns dos ícones, surgidos nas últimas três décadas, do que se poderia chamar de cultura queer. Ela se caracteriza, em linhas gerais, por se utilizar dos rótulos e clichês culturais em torno do universo LGBT para levar adiante discussões próprias a ele em relação aos tabus da sociedade, o que pudemos observar nos trabalhos do coletivo As Travestidas.

As cenas de BR Trans são ligadas por números musicais com inserções de vídeo que mostram o processo do ator-performer em reconhecer-se naquelas figuras. Desde a modificação do próprio rosto (com cabelos mais longos e lisos) até a exposição de corpos mortos de transexuais assassinados. O limite entre performance e o real, como já foi indicado, pois ali se tratava de uma evocação a essas tragédias.

Portanto, é uma forma de se religar a um trauma coletivo com raízes mais profundas do que podem se configurar nas palavras de ordem, não ditas, contra esses homens assassinos. Ocorre a purgação de um ódio, uma revolta (pessoal e social) e ao mesmo tempo sua exposição clara: "é difícil 
dançar com o diabo em suas costas", diz Silvero tentando se mover em uma espécie de baú com rodas, e quase caindo, dessa vez em uma referência à música Shake it out, do grupo inglês Florence + The Machine.

Em outro momento da peça, o performer mapeia em sua infância um desajuste entre as ordens do pai sobre como sentar-se ou portar-se e seu próprio universo de descobertas. Assume para a plateia uma carta escrita a sua mãe sobre suas escolhas de vida. Nesse ponto, ator e figura cênica se fundem novamente em uma dança que permeia esse trabalho, entre o ser ou não ser travesti. A mediação disso foi a escolha pela narração de histórias, algumas de sua vida.

\section{Desdobramentos e utopias}

Segundo Foucault, o corpo humano se torna um tipo de ator utópico ao sonhar-se diverso da sua condição mortal e precária. Assim, nas mitologias antigas, por exemplo, havia as figuras dos gigantes que dominariam a terra. O filósofo pensa uma série de utopias que dominam esse corpo e se voltam contra ele, mesmo que existam a partir da sua carnalidade. Em contraponto a isso:

Mascarar-se, maquiar-se, tatuar-se não é exatamente, como se poderia imaginar, adquirir outro corpo, simplesmente um pouco mais belo, melhor decorado, mais facilmente reconhecível [...]. Máscara, signo tatuado, pintura, depositam no corpo toda uma linguagem: toda uma linguagem enigmática, toda uma linguagem cifrada, secreta, sagrada, que evoca para este mesmo corpo a violência do deus, a potência surda do sagrado ou a vivacidade do desejo. (FOUCAULT, 2013, p. 12).

Parece-nos que os trabalhos Cabaré das travestidas e Quem tem medo de travesti? levam essa utopia da qual fala Foucault ao máximo e ao festivo, com seus números de cabaré entremeados de interações face a face com a plateia. Novamente, temos um tipo de bricollage de referências musicais para confundir os gêneros da própria arte. Onde está o erudito, o brega, o pop?

Esse trabalho é reflexivo, se arrisca a abismar-se, se deixa fruir na borda entre o entretenimento espetacular e o grotesco dos bufões. Sem deixar-se diluir como crítica aos poderes de uma linguagem dominante, em meio ao hu- 
mor e deboche, torna-se paródia de programas de auditório e do mainstream. Usa em sua estrutura um roteiro que passeia entre contos à la comédia stand up e narrativas musicais (em geral de divas pop ou cantoras norte-americanas, como Nicki Minaj, Jessie J, Mariah Carrey e Nina Simone), cantadas ou dubladas por Verônica Valentino e Mulher Barbada.

Essas formas também nos parecem mais próximas de uma carnavalização, que inverte tanto o cotidiano e o banal quanto poderes como o machismo, transitando entre o espetacular e o performativo ${ }^{4}$. Dessa maneira, esses trabalhos trazem cenas e músicas que tratam do universo biográfico, como quando Verônica nos fala de seu primeiro encontro com um primo na adolescência, cena que está presente em Quem tem medo de travesti?. Nesse momento, uma bailarina (Yasmin) se lança ao seu lado em movimentos embaraçados e vertiginosos, abrindo, em paralelo, outro espaço de narração, pelo equilíbrio e desequilíbrio de seu corpo que dança.

Contudo, outro tema pulsante retorna: o da denúncia, presente nesse último espetáculo. Se existe no Cabaré uma explosão, ela é contraposta pelo movimento de protesto e revolta trazidos por BR Trans, que trata dos limites entre o vivido na condição transexual e os efeitos de sua perseguição.

Já no começo da peça uma voz em off anuncia que está desistindo de viver, pois não consegue mais lidar com a carga emocional do preconceito, gravando uma mensagem para amigos e familiares; depois ouve-se um tiro. Não é preciso saber se era uma gravação original ou não, pois fomos informados na sequência sobre a morte de uma professora transexual, que tirou a própria vida. Ouvimos de Patricia Dawson a confirmação do tema que interessa a esse grupo; partimos, mais uma vez, daquilo que mais incomoda esses artistas, e vemos em seguida trechos de canções (uma delas é O mundo é um moinho, que remete ao amadurecimento e à melancolia dos que lutam para viver).

BR Trans também traz imagens e procedimentos que haviam sido experimentados desde os primeiros trabalhos do coletivo, mas destacamos aqui

4. Ainda que seja questionável, fazemos essa distinção ao associar o espetacular a uma lógica de conceber o teatro tanto como forma regrada e tradicional quanto show bizz. Já ao conceito de performativo consideramos o que Fèral (2008) pesquisa no teatro contemporâneo, como uma forma de busca por acontecimentos que tensionam ou imbricam ficção e vida real, deslocando a atenção do espectador para a ação gestual, a criação e a dissolução de signos. 
essa dinâmica de alternar momentos de maior gravidade com os de festa e carnavalização. Não vemos a presença de Silvero nas cenas, mas vemos outra forma de estar em cena dos demais atores, vestidos inicialmente com collants tom de pele. Desse grau zero são trazidos novos figurinos e números; em um deles as toalhas usadas pelos performers são postas em Alicia Pietá para um número de dublagem, e depois são jogadas fora por ela, como parte de um jogo.

Essa cena ocorre após uma questão ter sido levantada: o que resta a fazer diante das perseguições e adversidades pelas quais passam os sujeitos trans? Vemos assim a inserção do canto, das palavras endereçadas diretamente ao público e das dublagens como mais uma forma de desafiar esse preconceito tão poderoso e avassalador.

Daí, percebemos que montagem e desmontagem, vestir-se e trocar de roupa-pele, têm um significado importante, capaz de provocar um pensamento além do imediatamente visto e, unicamente, do universo transexual. Montar-se é vestir-se para sair, para a noite e seus riscos, mascarar-se com o sentido do corpo utópico foucaultiano. Assim, podemos pensar essa dinâmica das trocas aliadas a depoimentos e músicas como uma reflexão sobre o viver em meio à revolta e ao festejo, pelas mitologias trans que convocam à inversão e à mistura de gêneros. Segundo outro pensamento sobre novas formas de vida, deparamos com a seguinte ideia de Preciado:

Os órgãos que reconhecemos como naturalmente sexuais já são o produto de uma tecnologia sofisticada que prescreve o contexto em que os órgãos adquirem sua significação (relações sexuais) e de que se utilizam com propriedade, de acordo com sua "natureza" (relações heterossexuais). Os contextos sexuais se estabelecem por meio de delimitações espaço-temporais oblíquas. A arquitetura é política. É ela que organiza as práticas e as qualifica: públicas ou privadas, institucionais ou domésticas, sociais ou íntimas. (PRECIADO, 2015, p. 31)

Preciado, por exemplo, enxergou no corpo queer e na sua prótese, o dildo, uma nova forma de criar formas de sexualidade (ou de contrassexualidade), como na performance de Ron Athey, $O$ ânus solar ${ }^{5}$. Essa performatividade

5. Performance descrita por Preciado (2015) como uma "prática de inversão contrassexual," em que o performer exibe um vídeo em que lhe fazem uma tatuagem ao redor do ânus, 
do corpo e suas próteses (entendidas como símbolos de poder) de que nos falam suas teorias também está presente como movimentos, palavras, sons, objetos, máscaras, maquiagens e vestimentas nas cenas travestidas. Ou melhor: como não enxergar nesses travestimentos e mascaramentos uma nova e singular forma de vida e de teatro?

Também é importante destacar, ao que nos parece, que a presença das narrativas e das palavras diretas e até mesmo dos signos visuais e musicais rapidamente acessáveis pela memória do público é uma estratégia para combater preconceitos por meio do deboche de um clichê cultural de massa, e para se aproximar de novas arquiteturas corporais utópicas. Nesse caso, estamos considerando o contemporâneo como uma mistura de formas e procedimentos das artes cênicas que possam dar conta de tematizar uma experiência de vida e suas singularidades. Isso traz à tona fraturas de certa percepção filosófica da arte, cujo debate em termos de teatro e demais artes ainda estamos cartografando na cena cearense.

\section{Referências bibliográficas}

AMADOR, F.; FONSECA, T. M. G. Da intuição como método filosófico à cartografia como método de pesquisa: considerações sobre o exercício cognitivo do cartógrafo. Arquivos brasileiros de psicologia, v. 61, n. 1, 2009.

FÈRAL, J. Por uma poética da performatividade: o teatro performativo. Sala Preta, v. 8, 2008.

FOUCAULT, M. O corpo utópico, as heterotopias. São Paulo: n-1 edições, 2013. PRECIADO, B. Manifesto contrassexual. São Paulo: n-1 edições, 2015.

Recebido em 15/08/2015

Aprovado em 30/09/2015

Publicado em 21/12/2015

se escarifica no rosto, retira do ânus um colar de pérolas brancas, para logo depois masturbar-se com um dos dildos que carrega consigo. 